\title{
Die allokasie van die vraag na elektrisiteit met behulp van gemengde heeltallige programmering
}

\author{
C.A. Anderson \\ Elektrisiteitsafdeling, Stadsraad van Pretoria
}

W.G. Klerck

Skool vir Bedryfsleiding, Universiteit van Suid-Afrika, Pretoria

\begin{abstract}
The allocation of the demand for electricity using mixed integer programming. In this paper the authors have investigated the use of mixed integer programming to solve an allocation problem Ihat exists in the Electricity Department of the Pretoria Municipality. In the Pretoria supply area the demand for electricity is provided for by using the municipal power stations Rooiwal and Pretoria West and by obtaining power from Escom. Every year the Electricity Department must decide how the monthly demand (12 months ahead) for electricity must be allocated between their own power stations and the supply from Escom.

The allocation must be done in such a way that certain requirements are met. These requirements refer to the demand for electricity, the availability of the municipality's own generators, the capacity of the two power stations and a so called supply requirement laid down by Escom. A mixed in teger programming model was developed in which these requirements were catered for and in which the running costs were minimized. Results obtained thus far from the model indicate that it can provide the Electricity Department with a useful tool in solving a complicated allocation problem.

S. Afr. J. Bus. Mgmt. 1983, 14: $37-44$
\end{abstract}

In hierdie artikel word ondersoek ingestel na die gebruik van gemengde heeltallige programmering om ' $n$ allokasie probleem in die Elektrisiteitsafdeling van die Pretoriase Munisipaliteit op te los. In die Pretoriase toevoergebied word daar in die vraag na elektrisiteit voorsien deur twee munisipale kragsentrales, te wete Rooiwal en Pretoria-Wes te gebruik en deur elektrisiteit van Evkom aan te koop. Elke jaar moet die elektrisiteitsafdeling bepaal op welke wyse die maandelikse (12 maande vooruit) vraag na elektrisiteit tussen sy eie kragsentrales en die voorsiening van Evkom geallokeer moet word.

Die allokasie moet sodanig geskied dat aan sekere vereistes voldoen word. Hierdie vereistes het betrekking op die vraag na elektrisiteit, die beskikbaarheid van die munisipaliteit se eie krag generators, die kapasiteit van die kragsentrales en 'n sogenaamde invoerbeperking van Evkom. 'n Gemengde heeltallige programmeringsmodel is ontwikkel waarin al die vereistes as beperkinge geformuleer is en waarin die bedryfskostes geminimeer is. Voorlopige resultate toon dat die model wel nuttig deur die Elektrisiteitsafdeling aangewend kan word om ' $n$ ingewikkelde allokeringsprobleem op te los.

S. Afr. Tydskr. BedryfsI. 1983, 14: 37 - 44

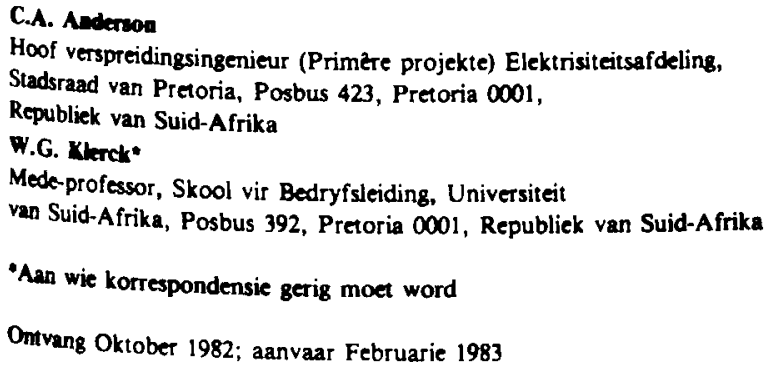

\section{Inleiding}

Die voorsiening van elektriese $\mathrm{krag}$ is een van die groot koste-items in die begroting van die Pretoriase munisipaliteit. Die energie-verwantekoste (hoofsaaklik steenkool en water) van hul eie kragsentrales en die totale koste verbonde aan Evkom aankope bedra ongeveer R83,5 miljoen vir die 1982/83 boekjaar. Aangesien die koste van elektrisiteitvoorsiening van so 'n groot omvang is, is dit wenslik om ondersoek in te stel na metodes om hierdie koste sover moontlik te minimeer.

\section{Probleemstelling}

In die Pretoriase toevoergebied word daar in die vraag na elektrisiteit voorsien deur twee munisipale kragsentrales, te wete Rooiwal en Pretoria-Wes, te gebruik en deur elektrisiteit van Evkom aan te koop. Die Pretoria-Weskragsentrale, wat reeds ongeveer 30 jaar in bedryf is, het ses turbogenerators terwyl daar by die Rooiwalkragsentrale, wat ongeveer 20 jaar in bedryf is, vyf turbogenerators is. Verder is ' $\mathrm{n}$ gasturbine onlangs by Pretoria-Wes geinstalleer. Elke jaar moet die munisipaliteit die vraag na elektrisiteit tussen sy eie kragsentrales en die voorsiening van Evkom allokeer en wel op so ' $n$ wyse dat die bedryfskoste tot ' $n$ minimum beperk word.

Die werklike allokasie van die vraag na elektrisiteit tussen verskillende kragvoorsieningseenhede is reeds onder andere deur Day' en Garver ${ }^{2}$ ondersoek. Genoemde skrywers het van lineêre-en heeltallige programmering gebruik gemaak om die probleem op te los.

In hierdie werkstuk sal daar ondersoek ingestel word na die gebruik van optimiseringsmodelle om bogenoemde probleem op te los.

Die gebruik van 'n model om die genoemde allokasie uit te voer noodsaak die keuse van 'n beplanningshorison. Volgens 'n ooreenkoms met Evkom moet in elke kalenderjaar die maandelikse invoer van elektrisiteit vanaf Evkom aan sekere vereistes voldoen. $O \mathrm{~m}$ die rede is die beplanningshorison op een jaar gestel en is dit verder in 12 afsonderlike maande onderverdeel. Die optimiseringsmodel sal dus onder andere bestaan uit 12 submodelle wat die allokasie van die vraag na elektrisiteit bepaal.

'n Belangrike komponent van die optimiseringsmodel is daardie beperkinge wat op die vraag na elektrisiteit betrekking het. Die vraag na elektrisiteit in 'n gegewe periode word met behulp van 'n lasduurkromme voorgestel. Alvorens die 
ontwikkeling van die optimiseringsmodel uiteengesit word, sal die gebruik van lasduurkrommes eers bespreek word.

\section{Dle lasduurkromme}

Maandelikse lasduurkrommes word gebruik om elektrisiteitsverbruik in 'n gebied voor te stel. Dit toon die tydsduur waarin die elektrisiteitslas 'n sekere waarde oorskry en is gewoonlik kromlynig. 'n Lasduurkromme vir 'n tipiese maand word in Figuur 1 getoon. Die kromme toon dat die aanvraag uitgestuur vir ' $n$ tydsduur $h$ (uur) die waarde $L_{h}$ (MW) oorskry. Die spitsaanvraag uitgestuur gedurende die maand word deur $L_{p}$ aangedui. Die minimum aanvraag $L_{b}$, dit wil sê die laagste minimum dagaanvraag, moet gedurende die volle aantal ure in die maand voorsien word en staan as die basislas bekend. Die energie (KWh) uitgestuur gedurende die maand word deur die oppervlakte onder die kromme voorgestel.

Om by linieêre programmering aanpasbaar te wees moet die lasduurkromme by benadering deur lineêre segmente voorgestel word. $\mathrm{Om}$ 'n geskikte benadering van die lasduurkromme te verkry en om die grootte van die model te beperk is vyf segmente gebruik. Die keuse van vyf segmente is tot 'n mate arbitrêr en sal in die toekoms verdere aandag geniet.

Die segmentering is sodanig gedoen dat die oppervlakte van 'n segment $(\mathrm{kWh})$ gelykstaande is aan die oppervlakte onder die kurwe vir die betrokke tydsduur. Die indeling van die segmente is in hierdie ondersoek vir 'n tipiese maand

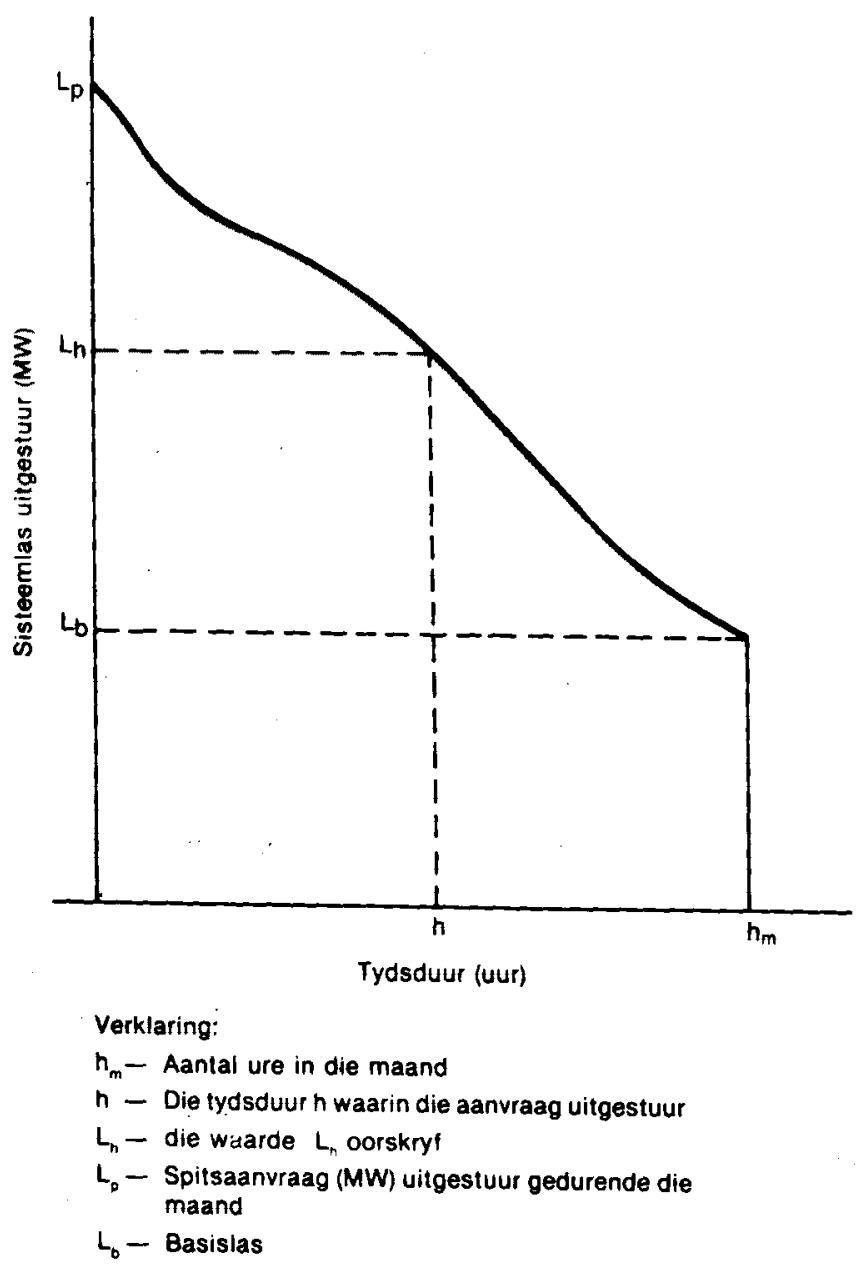

Fgaur 1 Lasduurkromme vir 'n tipiese maand
Tabel 1

\begin{tabular}{cccc} 
Segment & $\begin{array}{c}\text { Kumulatiewe tydsduur } \\
\text { nr }\end{array}$ & \multicolumn{2}{c}{ Tipiese lasvereistes } \\
\cline { 4 - 5 } & segment (uur) & $\%$ & MW \\
\hline 1 & 1 & 100,0 & 725 \\
2 & 50 & 96,5 & 693 \\
3 & 200 & 86,0 & 624 \\
4 & 400 & 74,5 & 540 \\
5 & 744 & 49,2 & 357 \\
\hline
\end{tabular}

met 31 dae (744 uur) en 'n spitslas van $725 \mathrm{MW}$ gedoen soos in Tabel 1 getoon.

Vir een uur in 'n maand met 31 dae moet die elektrisiteit gelewer minstens $725 \mathrm{MW}$ wees. Vir 744 uur moet die elektrisiteit gelewer minstens $357 \mathrm{MW}$ wees.

\section{Die optimiseringsmodel}

Die veranderlikes

Die veranderlikes in die model kan in vier groepe verdeel word en het betrekking op:

(a) Die aantal turbogenerators wat loop.

(b) Die uitset van die turbogenerators bo die minimum uitset.

(c) Die Evkom-invoer.

(d) Die uitset van die gasturbine.

\section{Die aantal turbogenerators wat loop}

Die eerste groep veranderlikes verwys na die aantal generators te Rooiwal en Pretoria-Wes wat in elke maand van die jaar en in elke segment van die lasduurkromme loop. Vir Rooiwal en Pretoria-Wes word die volgende stel veranderlikes dus gedefinieer:

$\mathrm{N}(\mathrm{M}, \mathrm{S}, \mathrm{U})$ - Die aantal tipe U generators wat in maand $\mathrm{M}$ in segment $\mathrm{S}$ van die lasduurkromme loop.

$$
\begin{aligned}
& \mathrm{M}=1,2, \ldots 12 \\
& \mathrm{~S}=1,2, \ldots 5 \\
& \mathrm{U}=\mathrm{B}, \mathrm{R}
\end{aligned}
$$

Wanneer die indeks $U$ gelyk is aan $B$ verwys dit na die generators van Pretoria-Wes en wanneer $U$ gelyk is aan $R$ verwys dit na die generators te Rooiwal. In die model word daar dus net voorsiening vir twee tipe turbogenerators gemaak.

\section{Die uitset van die turbogenerators}

'n Turbogenerator kan slegs tussen 'n minimum en 'n maksimum leweringsvlak bedryf word. Om dié rede is daar 'n groep veranderlikes wat verwys na die uitsetvlak bo die minimum uitset.

Indien ' $n$ generator in bedryf geplaas word moet dit ten minste 'n minimum drywing $V(U)$ lewer. Die drywing wat generator tipe $U$ bo die minimum $V(U)$ lewer word deur $\mathbf{X}(\mathrm{M}, \mathrm{S}, \mathrm{U})$ aangedui. Die waardes wat $\mathrm{X}(\mathrm{M}, \mathrm{S}, \mathrm{U})$ kan aanneem, word onder andere bepaal deur die aantal tipe $U$ generators wat aangeskakel is. Indien daar net een tipe $U$ generator aangeskakel is $\operatorname{kan} X(M, S, U)$ enige waarde tussen nul en een aanneem. Wanneer $X(M, S, U)$ gelyk is aan nul en $\mathbf{N}(M, S, U)$ gelyk is aan een, dan lewer tipe U-generator die minimum uitset $\mathrm{V}(\mathrm{U})$. As $\mathrm{X}(\mathrm{M}, \mathrm{S}, \mathrm{U})$ gelyk is an 1,0 
lewer tipe U-generator die maksimum uitset $W(U)$. 'n $\mathrm{X}(\mathrm{M}, \mathrm{S}, \mathrm{U})$ waarde van 0,5 toon aan dat die generator 'n uitset halfpad tussen $V(U)$ en $W(U)$ lewer. Wanneer daar, sê q tipe U-generators is, dan $\operatorname{kan} \mathrm{X}(\mathrm{M}, \mathrm{S}, \mathrm{U})$ enige waarde tussen 0 en $q$ aanneem.

\section{Evkom-invoer}

Ingevolge 'n konsep-ooreenkoms tussen Evkom en die Stadsraad van Pretoria word Evkom se standaardtarief toegepas. Die hoofkomponente van die tarief is ' $n$ maandelikse aanvraagheffing (Rand per $\mathrm{kW}$ ) en ' $\mathrm{n}$ energieheffing (sent per $\mathrm{kWh}$ ). Aangesien die Stadsraad van Pretoria die hooftransformator by die Kwagga-invoerstasie voorsien het, word ' $n$ spesiale afslag op die aanvraagheffing toegepas. Die konsep-ooreenkoms maak ook voorsiening vir wedersydse bystand. Ingevolge hierdie klousule word 56 megawatt sonder aanvraagheffing teen slegs 'n energieheffing elke maand met uitsondering van Junie, Julie en Augustus aan die Stadsraad gelewer; dit is indien Evkom die nodige reserwe-ontwikkelingskapasiteit beskikbaar het.

Vir die ontwikkeling van die model kan die Evkom-invoer as twee afsonderlike invoere beskou word. By die eerste invoer word daar vir aanvraag en energieverbruik betaal. By die tweede invoer is die aanvraag komponent gratis. Twee kontinue veranderlikes word dus benodig om die drywing ingevoer van Evkom voor te stel:

(a) $\mathrm{E}(\mathrm{M}, \mathrm{S})$ - Drywing (gemeet in $\mathrm{MW}$ ) ingevoer vanaf Evkom in segment $S$ en maand $M$

(b) $\mathrm{F}(\mathrm{M}, \mathrm{S})$ - Gratis drywing ingevoer vanaf Evkom in segment $S$ en maand $M$

Gasturbine-uitset

Die vierde groep veranderlikes verwys na die drywing gelewer deur die gasturbine in elke maand en in elke segment van die lasduurkromme:

$G(M, S)$ - Drywing gelewer deur die gasturbine in maand $M$ en in elke segment $S$ van die lasduurkromme.

Met die uitsondering van die eerste groep veranderlikes is al die veranderlikes kontinu.

\section{Die beperkinge}

Die beperkinge in die model het betrekking op die volgende:

(a) Die beskikbaarheid van die generators

(b) Die lasvereistes

(c) Die aansitbeperkinge vir die generators

(d) Sekerheidsbeperking

(e) Gasturbine-kapasiteit

(f) Invoerbeperking

\section{Die beskikbaarheid van die generators}

Die aantal generators van elke tipe wat gebruik word om krag te lewer kan nie meer wees as wat beskikbaar is nie:

$\mathrm{N}(\mathrm{M}, \mathrm{S}, \mathrm{U}) \leq \mathrm{A}(\mathrm{M}, \mathrm{U})$ waar $\mathbf{A}(\mathbf{M}, \mathrm{U})$ die aantal tipe U-generators beskikbaar in maand $M$ is.

Vir elke maand van die jaar, vir elke segment van die lasduurkromme en vir elke tipe generator moet daar dus ' $n$ beskikbaarheidsbeperking wees. Dit beteken dat daar 120 $(12 \times 5 \times 2)$ beskikbaarheidsbeperkinge moet wees. Die aan- tal beskikbaarheidsbeperkinge kan tot 24 ( 2 per maand) verminder word indien aanvaar word dat ' $n$ generator wat in 'n gegewe maand in segment $\mathrm{S}$ van die lasduurkromme krag lewer ook in segmente waar groter lasvereistes voorkom, krag sal lewer. Die beskikbaarheidsbeperking reduseer dan tot:

$\sum_{S=1}^{S} N(M, S, U) \leq A(M, U)$

Die lasvereistes

Daar moet ' $n$ stel beperkinge wees wat toesien dat die drywing wat plaaslik ontwikkel word en vanaf Evkom ingevoer word, voldoende is om in die totale aanvraag te voorsien. Dié beperkinge word gegee deur die uitdrukking:

$\sum_{U} \mathrm{~V}(\mathrm{U}) \mathrm{N}(\mathrm{N}, \mathrm{S}, \mathrm{U})+\mathrm{W}(\mathrm{U})-\mathrm{V}(\mathrm{U}) \cdot \mathrm{X}(\mathrm{M}, \mathrm{S}, \mathrm{U})$

$+\sum_{\mathrm{I}=\mathrm{S}}^{S} \mathrm{E}(\mathrm{M}, \mathrm{I})+\sum_{\mathrm{I}=\mathrm{S}}^{S} \mathrm{~F}(\mathrm{M}, \mathrm{I})+\mathrm{G}(\mathrm{M}, \mathrm{I}) \geq \mathrm{L}(\mathrm{M}, \mathrm{S})$

waar $\mathrm{L}(\mathbf{M}, \mathrm{S})$ - die lasvereiste in maand $\mathrm{M}$ en in segment $\mathrm{S}$ van die lasduurkromme.

Die uitdrukking $\mathrm{V}(\mathrm{U})$. $\mathrm{N}(\mathrm{M}, \mathrm{S}, \mathrm{U})$ gee die minimum uitset gelewer deur die tipe $U$-generator in maand $M$ en in segment $S$ van die lasduurkromme. Die uitdrukking $(W(U)-$ $V(U)) X(M, S, U)$ gee die drywing gelewer deur die generators $\mathrm{U}$ bo die minimum uitset.

Die aanvraagkoste verbonde aan die Evkom-invoer moet by elke segment van die lasduurkromme in berekening gebring word. Die drywing wat in 'n gegewe maand in segment $S$ ingevoer word sal ook in segmente waar groter lasvereistes voorkom beskikbaar wees. Die maandelikse spitsaanvraag ingevoer vanaf Evkom sal dus gelyk wees aan die som van die drywing ingevoer vir segmente 1 tot 5 . Vandaar die uitdrukking

$\sum_{I=S}^{S} E(M, I)$ en $\sum_{i=S}^{S} F(M, I)$.

Indien die beskikbaarheidsbeperkinge geformuleer word soos in vergelyking 1 aangetoon, reduseer die lasvereistes tot:

$$
\begin{aligned}
& \sum_{U} V(U) \sum_{i=S}^{S} N(M, I, U)+(W(U)-V(U)) X(M, S, U) \\
& \quad+\sum_{i=S}^{S} E(M, I)+\sum_{i=S}^{S} F(M, I)+\sum_{i=s}^{S} G(M, I) \geq L(M, S)
\end{aligned}
$$

Die aanname met betrekking tot die beskikbaarheidsbeperking geld dus ook ten opsigte van die gasturbine. Vandaar die uitdrukking $\Sigma_{I} G(M, I)$ in bogenoemde vergelyking 2.

\section{Aansitbeperkinge}

Alvorens 'n generator krag kan lewer moet dit eers aan die gang gesit word. Om dus te voorkom dat 'n generator krag lewer sonder dat dit aan die gang is word die volgende stel beperkinge geformuleer:

$X(M, S, U)-\sum_{i=S}^{S} N(M, I, U) \leq 0$

\section{Sekerheidsbeperking}

By die Pretoria-Weskragsentrale word daar om sekerheidsredes minstens een generator in bedryf gehou. Dus

$N(M, S, B) \geq 1$ 
Aangesien N(M,5,B) groter of gelyk aan een is, impliseer dit dat minstens een generator in segment vyf van die lasduurkromme krag lewer en dus ook in al die ander segmente; dit wil sê minstens een Pretoria-Wes generator lewer in elke maand van die jaar altyd krag.

\section{Gasturbinekapasiteit}

Indien die maksimum kapasiteit van die gasturbine $\mathbf{P}(\mathbf{M})$ is dan geld die volgende:

$$
\begin{gathered}
\sum_{\mathbf{S}} G(\mathbf{M}, \mathbf{S}) \leq \mathrm{P}(\mathbf{M}) \\
\mathbf{M}=1,2, \ldots, 12 \\
\mathbf{S}=1,2, \ldots, 5
\end{gathered}
$$

\section{Invoerbeperking}

Om te verhoed dat die drywing uitgestuur gedurende die spits maande (gewoonlik die wintermaande) veel hoër is as gedurende die nie-spitsmaande, het Evkom 'n reduksiefaktorklousule in die ooreenkoms vir die lewering van elektrisiteit aan Pretoria. In die klousule word bepaal dat die Evkom-invoer so gereguleer moet word dat die verhouding van die gemiddelde maandelikse aanvraag ingevoer gedurende ' $n$ kalenderjaar tot die maksimum maandelikse aanvraag ingevoer minstens gelykstaande moet wees aan 'n reduksiefaktor. Die waarde van die reduksiefaktor is tans 0,833 . Dit impliseer dat die toename in die drywing ingevoer gedurende die spitsmaand nie meer moet wees as $20 \%$ van die gemiddelde maandelikse drywing ingevoer nie. Indien daar nie aan hierdie klousule voldoen word nie, word 'n bykomende bedrag in die daaropvolgende kalenderjaar teen die Stadsraad gehef. Dit beteken dat daar dan tot 'n mate vir Evkom-aanvraag betaal moet word sonder dat daar energiever bruik was. Die omvang van die penalisering is baie groot en kan meer as R1 miljoen bedra.

Hierdie beperking word gegee deur die uitdrukking

$\frac{\sum_{\mathbf{M}} \sum_{S} \mathrm{E}(\mathrm{M}, \mathrm{S}) / 12}{\sum_{\mathrm{S}} \mathrm{E}(\mathrm{P}, \mathrm{S})} \geq \mathrm{T}$

waar $\mathrm{P}$ die spitsmaand en $\mathrm{T}$ die reduksiefaktor is.

Apriori kan daar egter nie met sekerheid bepaal word watter maand die spitsmaand is nie. Ten einde die probleem te oorbrug word elke maand as 'n potensiële spitsmaand beskou en gevolglik is daar dan 12 beperkinge naamlik

$\frac{\sum_{M} \sum_{S} E(M, S) / 12}{\sum_{S} E(P, S)} \geq T \quad P=1,2, \ldots, 12$

Dié uitdrukking vereenvoudig na

$$
\begin{aligned}
12 \mathrm{~T} \sum_{S} E(P, S)-\sum_{M} \sum_{S} E(M, S) & \leq 0 \\
P & =1,2, \ldots, 12
\end{aligned}
$$

\section{Die doelfunksie}

Die doelfunksie in die betrokke model is ' $n$ uitdrukking van die totale 'bedryfskoste' en die oplossing van die model sal hierdie koste minimeer. Die 'bedryfskoste' bestaan uit die volgende komponente:

(a) Lopende koste van turbogenerators

(b) Koste van Evkom-invoer

(c) Lopende koste van die gasturbine
Lopende koste van turbogenerators

Die lopende koste van die turbogenerators is die maandelikse veranderlike koste en sluit items soos steenkoolkoste en koste van waterverbruik in. Vanweë die samestelling van die model moet daar onderskei word tussen die lopende koste van 'n turbogenerator teen minimum uitset $\left(C_{v}\right)$ en die lopende koste, bo en behalwe die koste teen minimum uitset, verbonde aan die gebruik van een tur. bogenerator teen maksimum uitset $\left(\mathrm{C}_{w}\right)$. Die kostekoëffisiente $C_{v}$ en $C_{w}$ word in Rand per MW uitgedruk.

\section{Koste van Evkom-invoer}

Die koste verbonde aan die Evkom-invoer $(E(M, S))$ is die maandelikse koste ten opsigte van die maksimum aanvraag vir die betrokke maand en die energieverbruik gedurende die maand. Die Evkom kostekoeffisient $C_{E}$ is bogemelde koste uitgedruk in Rand per MW. Die 'gratis' Evkom drywing se koste word voorgestel deur die kostekoëffisient $C_{F}$.

\section{Lopende koste van gasturbine}

Die lopende koste van die gasturbine is die maandelikse veranderlike koste en bestaan hoofsaaklik uit die koste van die dieselbrandstof. Die gasturbine koste-koëffisient $C_{G}$ is die maandelikse grenskoste uitgedruk in Rand per MW.

Die volledige doelfunksie is soos volg:

Minimeer $\sum_{M} \sum_{U} \sum_{S}\left(C_{v}(M, S, U) . N(M, S, U)+C_{w}(M, S, U)\right.$. $\mathrm{X}(\mathrm{M}, \mathrm{S}, \mathrm{U}))+\sum_{M} \sum_{S} C_{E}(\mathbf{M}, \mathrm{S}) . \mathrm{E}(\mathrm{M}, \mathrm{S})+\sum_{M} \sum_{S} C_{F}(M, S)$.

$F(M, S)+\sum_{M} \sum_{S} C_{G}(M, S) \cdot G(M, S)$

Die uitdrukking $C_{v}(M, S, U)$. N(M,S,U) gee die lopende koste van die tipe U-generators teen minimum uitset in maand $M$ en in segment $S$ van die lasduurkromme (segmente met hoër lasvereistes ingesluit). Die lopende koste bo en behalwe die koste teen minimum uitset verbonde aan die gebruik van die tipe U-generators teen werklike uitset in maand $M$ en in segment $S$ van die lasduurkromme word deur $C_{w}(M, S, U)$. X(M,S,U) gegee.

Die uitdrukkings $C_{E}(M, S)$. $E(M, S), C_{F}(M, S) F(M, S)$ en $\mathrm{C}_{\mathrm{G}}(\mathbf{M}, \mathrm{S})$. $\mathrm{G}(\mathbf{M}, \mathrm{S})$ gee die respektiewelike koste verbonde aan die Evkom-invoer, die gratis Evkom-invoer en die gebruik van die gasturbine in maand $M$ en in segment $S$ van die lasduurkromme (segmente met hoër lasvereistes ingesluit).

Die model word in bylaag een saamgevat. Die model bestaan onder andere uit

- 252 beperkinge

- 120 heelgetal veranderlikes

- 300 kontinue veranderlikes.

Die data wat benodig word om die model in werking te stel sal vervolgens behandel word.

\section{Die data}

Die data wat vir die model benodig word is:

- die beskikbare turbogenerators $A(M, U)$ (sien vergelyking 1)

- Die minimum V(U) en maksimum W(U) kapasiteite vir elke tipe generator (sien vergelyking 2 )

- Die lasvereistes L(M,S) (Sien vergelyking 2) 
- Die kapasiteit $P(M)$ van die gasturbine (sien vergelyking 5)

- Die koste-koëffisiënte (sien vergelyking 7)

Die wyse waarop bogenoemde inligting bekom en bereken is sal nie in hierdie artikel in detail uiteengesit word nie. Anderson $^{3}$ gee ' $n$ volledige uiteensetting van al die nodige berekenings. Waar nodig sal daar in dié artikel slegs 'n kort uiteensetting gegee word van die berekenings.

\section{Die beskikbare generators}

Te Rooiwal en Pretoria-Wes is daar onderskeidelik ' $n$ maskimum van vyf en ses generators beskikbaar. Weens geskeduleerde onderhoud en ander onvoorsiene omstandighede sal al die generators nie elke maand beskikbaar wees nie.

\section{Kapasiteite van die generators}

Die maksimum kapasiteit van ' $n$ generator is $25 \mathrm{MW}$ te Pretoria-Wes en $56 \mathrm{MW}$ te Rooiwal. Die minimum uitset waarteen ' $\mathrm{n}$ generator bedryf word is $12 \mathrm{MW}$ te PretoriaWes en 35 MW te Rooiwal.

\section{Die lasvereistes}

Die lasvereistes in elke segment en vir elke kalendermaand vir 1983 is as volg beraam:

(a) 'n Genormaliseerde maandelikse lasduurkromme word bepaal.

(b) Die uurspitsaanvraag (segment 1) word vir elke maand in 1983 beraam.

(c) Met behulp van die genormaliseerde maandelikse lasduurkromme en die beraamde uurspitsaanvraag word die lasvereistes in die ander segmente bepaal.

\section{Genormaliseerde lasduurkrommes}

Met behulp van historiese data (boekjare 1969/701977/78) word 'n genormaliseerde maandelikse lasduurkromme vir elke kalendermaand bepaal. Die genormaliseerde lasduurkromme toon aan watter persentasie van die sisteemlas in elke segment voorkom asook die tydsduur van elke segment. In Tabel 2 word byvoorbeeld ' $n$ gemiddelde lasduurkromme vir Meimaand getoon. In segment 2 is die lasvereistes byvoorbeeld $95,6 \%$ van die spitsaanvraag.

\section{Beraming van die uurspitsaanvraag (segment 1)}

Die uurspitsaanvraag vir elke maand in 1983 is beraam deur gebruik te maak van die funksie

$\mathrm{y}=\mathbf{a} \mathrm{e}^{\mathbf{b x}}$

waar $y$ - uurspitsaanvraag

$\mathrm{x}$ - jaar

Tabel 2 'n Genormaliseerde lasduurkromme

\begin{tabular}{ccc}
$\begin{array}{c}\text { Segment } \\
\text { nr. }\end{array}$ & $\begin{array}{c}\text { Sisteemlas } \\
\%\end{array}$ & $\begin{array}{c}\text { Tydsduur } \\
\text { (uur) }\end{array}$ \\
\hline 1 & 100 & 1 \\
2 & 95,6 & 49 \\
3 & 86,0 & 150 \\
4 & 74,5 & 200 \\
5 & 49,2 & 344 \\
\hline
\end{tabular}

Data vir die periode 1971 tot 1982 is gebruik om die parameters $a$ en $b$ te beraam.

\section{Die lasvereistes in die ander segmente}

Die lasvereistes in segmente twee tot vyf is grafies bepaal sodat die oppervlakte onder die betrokke deel van die lasduurkromme dieselfde is as die oppervlakte ingesluit deur die segment. Met behulp van die beraamde uurspitsaanvraag word die sisteemlas in elk van die ander segmente bereken.

\section{Die kapasiteit van die gasturbine}

Die kapasiteit $P(M)$ van die gasturbine in elke maand vir alle segmente is $25 \mathrm{MW}$ onder normale omstandighede.

\section{Koste-koëffisiente}

Die koëffisiente in die doelfunksie (sien vergelyking 7) verwys na:

- die lopende koste $C_{v}(M, S, U)$ van die turbogenerator teen minimum uitset

- die lopende koste $C_{w}(M, S, U)$ van 'n turbogenerator teen maksimum uitset (bo en behalwe die koste teen minimum uitset)

- die koste $C_{E}(M, S)$ van die Evkom-invoer

- die koste $C_{F}(M, S)$ van die 'gratis' Evkom-invoer

- die lopende koste $C_{G}(M, S)$ van die gasturbine.

Ten einde die minimum lopende koste $C_{V}(M, S, U)$ en die maksimum lopende koste $C_{w}(M, S, U)$ vir elke tipe turbogenerator te bepaal, is dit eers nodig om die maandelikse grenskoste (uitgedruk in $\mathrm{c} / \mathrm{kWh}$ ) te bereken. Aangesien die maandelikse grenskostedata vir die plaaslike kragsentrales nie bekend is nie word die gemiddelde jaarlikse grenskoste (ook genoem die energieverwantekoste) as 'n aanduiding van dié koste geneem. Die gemiddelde jaarlikse grenskoste (dit sluit hoofsaaklik steenkool en water in) vir Pretoria-Wes en Rooiwal is beraam op $1,599 \mathrm{c} / \mathrm{kWh}$ en $1,0265 \mathrm{c} / \mathrm{kWh}$ onderskeidelik; dit is vir die kalenderjaar 1983.

\section{Die lopende koste $C_{v}(M, S, U)$}

Die waarde $C_{v}$ (segemente met hoër lasvereistes ingesluit) in enige gegewe maand vir enige gegewe segment word gegee deur die produk van

- die kumulatiewe tydsduur (ure) van die segment

- minimum uitset van die generator (MW)

- energieverwante koste ( $R / M W h)$

Aangesien die tydsduur vir segmente een tot vier van dic lasduurkromme vir alle maande dicselfde is, is die waardes van $C_{v}$ vir segmente een tot vier dieselfde.

Die lopende koste $C_{w}(M, S, U)$

Die lopende koste $C_{w}(M, S, U)$ van 'n turbogenerator teen maksimum uitset (bo en behalwe die koste teen minimum uitset) word op 'n dergelike wyse as $C_{v}$ bereken.

Die koste $C_{E}(M, S)$ van die Evkom-invoer

Die Evkomtarief is basies 'n tweeledige tarief te wete 'n aan vraagverwante koste en 'n energieverwante koste. Laasgenoemde koste word normaalweg deur Evkom kwartaalliks aangepas.

Die totale Evkom koste (R/MW) vir elke segment en in elke maand word gegee deur die som van die aanvraaghef fing en die energiekoste. Die energiekoste word gegee deur 
Tabel 3 Allokasie van die 1983 vraag na elektrisiteit

\begin{tabular}{|c|c|c|c|c|c|c|c|c|c|}
\hline \multirow[b]{2}{*}{ Maand } & \multicolumn{2}{|c|}{ Stelsel as geheel } & \multicolumn{3}{|c|}{ Pretoria-Wes } & \multicolumn{2}{|c|}{ Rooiwal } & \multicolumn{2}{|c|}{ Evkom" } \\
\hline & $\begin{array}{c}\text { Aanvraag } \\
\text { MW }\end{array}$ & $\begin{array}{c}\text { Energie } \\
\text { GWH }\end{array}$ & $\begin{array}{l}\text { Aan- } \\
\text { vraag } \\
\text { Turbo }\end{array}$ & Gas & $\begin{array}{l}\text { Energie } \\
\text { GWH }\end{array}$ & $\begin{array}{c}\text { Aanvraag } \\
\text { MW }\end{array}$ & $\begin{array}{c}\text { Energie } \\
\text { GWH }\end{array}$ & $\begin{array}{c}\text { Aanvraag } \\
\text { MW }\end{array}$ & $\begin{array}{c}\text { Energie } \\
\text { GWH }\end{array}$ \\
\hline Januarie & 557 & 287 & 23 & - & 9 & 224 & 167 & 310 & 111 \\
\hline Februarie & 588 & 286 & 25 & - & 8 & 224 & 150,5 & 339 & 127 \\
\hline Maart & 586 & 312 & 12 & - & 9 & 224 & 167 & 350 & 136 \\
\hline April & 614 & 307 & 12 & - & 9 & 224 & 161 & 378 & 137 \\
\hline Mei & 661 & 327 & 27 & - & 9 & 224 & 167 & 409 & 152 \\
\hline Junie & 782 & 383 & 125 & 23 & 47 & 280 & 202 & 354 & 161 \\
\hline Julie & 784 & 394 & 125 & 25 & 150 & 280 & 208 & 354 & 166 \\
\hline Augustus & 716 & 353 & 72 & - & 11 & 280 & 208 & 354 & 134 \\
\hline September & 628 & 306 & 45 & - & 9 & 224 & 161 & 359 & 136 \\
\hline Oktober & 608 & 320 & 75 & - & 56 & 224 & 167 & 309 & 98 \\
\hline November & 554 & 289 & 75 & - & 54 & 224 & 161 & 255 & 74 \\
\hline Desember & 571 & 279 & 75 & - & 50,1 & 224 & 167 & 272 & 62 \\
\hline
\end{tabular}

Die gratis Evkomdrywing van $56 \mathrm{MW}$ is behalwe vir Junie, Julie en Augustus, hierby ingesluit. Vir Junie tot Augustus is dit nie beskikbaar nie.

die produk van die energieheffing en die kumulatiewe tydsduur van die betrokke segment.

\section{Die koste $C_{F}(M, S)$ van die 'gratis' Evkom-invoer}

Die koste van die 'gratis' Evkom-invoer word gegee deur die produk van die energieheffing en die kumulatiewe tydsduur van elke segment. Die aanvraagheffing is dus by dié koste uitgesluit.

\section{Die lopende koste $C_{G}(M, S)$ vir die gasturbine}

Ten einde die lopende koste $\mathrm{C}_{\mathrm{G}}(\mathrm{M}, \mathrm{S})$ vir die gasturbine te bepaal, is dit eers nodig om die maandelikse grenskoste (uitgedruk in $\mathrm{c} / \mathrm{kWh}$ ) te bereken. Aangesien die maandelikse grenskostedata vir die gasturbine nie bekend is nie word die verwagte gemiddelde jaarlikse brandstofkoste as ' $n$ tydelike maatreël gebruik. Dié verwagte koste (energieverwante koste) vir 1983 is $15,37 \mathrm{c} / \mathrm{kWh}$. Die lopende koste $\mathrm{C}_{\mathrm{G}}(\mathrm{M}, \mathrm{S})$ vir die gasturbine word gegee deur die produk van die energieverwante koste en die kumulatiewe tydsduur vir elke segment.

\section{Probleemoplossing}

Die rekenaaroplossing wat met gebruik van bostaande data vir 1983 verkry is, word in Tabel 3 kortliks saamgevat. Die volgorde waarin die kragbronne benut moet word is soos volg: Rooiwal, Evkom, Pretoria-Wes en daarna die gasturbine.

\section{Rooiwalkragsentrale}

Die oplossing toon dat Rooiwal deurgaans in alle maande ten volle benut moet word. Rooiwal moet dus die grootste moontlike deel van die basislas voorsien (sien Figuur 1).

\section{Evkom-invoer}

Die Evkom-invoer moet gebruik word om na Rooiwal die res van die basislas en 'n groot deel van die verdere las te voorsien. Gedurende die laaste kwartaal verkry PretoriaWes prioriteit bo Evkom.

Die oordeelkundige bepaling van die Evkom-mikpunte is 'n kritiese belangrike bestuurstaak want dié mikpunte lê die grondslag vir die ekonomiese beheer van die kragbronne. Tans word die Evkom-mikpunte twee of driekeer per jaar gewysig. Die rekenaaroplossing toon dat dit bykans elke maand aangepas behoort te word.

\section{Pretoria-Weskragsentrale}

Gedurende die eerste vyf maande word Pretoria-Wes so te sê slegs om sekerheidsredes gebruik. Gedurende Junie en Julie is die benutting hoog tydens spitstye. Gedurende Augustus en September is die benutting weer laag, ook tydens spitstye. Gedurende die laaste kwartaal word Pretoria-Wes ten volle gebruik om 'n deel van die basislas te voorsien. Hierdie ommekeer vind plaas omdat die Evkomenergiekoste gedurende die laaste kwartaal $(1,605 \mathrm{c} / \mathrm{kWh})$ hoër is as die gemiddelde energieverwante koste vir Pretoria-Wes vir $1983(1,5990 \mathrm{c} / \mathrm{kWh})$.

\section{Gasturbine}

Die oplossing toon dat die gasturbine slegs gedurende Junie en Julie benut moet word. Die energie-uitset moet uiters laag wees.

\section{Reduksiefaktorklousule}

Volgens die optimale oplossing is vier van die twaalf invoerbeperkinge (Mei tot Augustus) bindend. In elk van dié maande is die drywing gelewer deur Evkom $354 \mathrm{MW}$. Daar is dus 4 'spitsmaande' sover dit die Evkom-invoer betref en is dit dus noodsaaklik om meer as een invoerbeperking te hê. Die styging in die drywing gelewer gedurende dié maande is beperk to $20 \%$ van die twaalf maandelikse gemiddelde. Sonder die invoerbeperking sou die styging in die invoer $20 \%$ oorskry het en sou die Stadsraad onderhewig wees aan die betaling van ' $n$ boete.

\section{Evaluering van die oplossing}

Die grootste tekortkoming in die huidige model-oplossing is die feit dat die beskikbare generators te Rooiwalkragsentrale deurgaans ten volle benut moet word. Aangesien dit 
om praktiese redes nie moontlik is om 'n kragsentrale so te bedryf nie is dit noodsaaklik om die model te wysig.

Een moontlike oplossing vir dié probleem is om die volle uitset van $56 \mathrm{MW}$ van die Rooiwalgenerators te verminder; dit wil sê die koëffisiënt $W(U)$ in vergelyking (2) aan te pas. 'n Ander moontlikheid is om die Rooiwalgenerators in sekere segmente van die lasduurkromme slegs teen minimum uitset te bedryf. Op die wyse sal die benutting van die kragsentrale verminder kan word.

'n Verdere moontlike tekortkoming in die model is die gebruik van Pretoria-Wes om gedurende die laaste kwartaal ' $n$ deel van die basislas te voorsien. Hierdie verskynsel kan hoofsaaklik toegeskryf word aan die feit dat die gemiddelde energieverwante koste vir 1983 vir Pretoria-Wes laer is gedurende die laaste kwartaal as die koste van Evkomkrag. Indien die werklike maandelikse energiekoste gebruik word en nie 'n gemiddelde twaalf maandelikse energiekoste nie mag die verskynsel moontlik nie voorkom nie. Hierdie aspek sal verder ondersoek moet word alvorens 'n finale besluit geneem kan word.

Volgens die elektrisiteitsafdeling van die Stadsraad moet daar gedurende April tot Oktober 'n hoër draaiende reserwe te Pretoria-Wes bestaan. (Draaiende reserwe is die oormaat kragontwikkelingstoerusting wat met die kragstelsel gesinchroniseer is en wat gereed is om onmiddellike ontwikkeling te verskaf.) Die model maak tans voorsiening daarvoor dat een turbogenerator te Pretoria-Wes te alle tye beskikbaar is. Dié beskikbaarheid kan verhoog word deur beperking (4) ooreenkomstig die behoeftes aan te pas.

\section{Samevatting}

Met die uitsondering van bogenoemde tekortkominge strook die oplossing van die model basies met die huidige beleid waarvolgens kragbronne benut word. Die model bied 'n maklik implementeerbare metode waarvolgens die maandelikse Evkom-mikpunte bereken kan word. Dit kan ook gebruik word (mits die nodige inligting beskikbaar is) om 'n vooruitskatting van die minimum jaarlikse bedryfskoste te verkry.

Die model kan as 'n nuttige hulpmiddel deur die Pretoriase Elektrisiteitsafdeling gebruik word om 'n ingewikkelde allokasie probleem op te los. Aangesien algemeen beskikbare rekenaarprogrammateur gebruik is, kan so 'n model deur ander munisipaliteite waar daar 'n soortgelyke samestelling van kragbronne bestaan, benut word.

\section{Summary}

In this paper the authors have investigated the use of mixed integer programming to solve an allocation problem that exists in the Electricity Department of the Pretoria Municipality. In the Pretoria supply area the demand for electricity is provided for by using the municipal power stations Rooiwal and Pretoria West and by obtaining power from Escom. Every year the Electricity Department must decide how the monthly demand ( 12 months ahead) for electricity must be allocaled between their own power stations and the supply from Escom.

The allocation must be done in such a way that total running costs are minimized subject to certain constraints. These constraints refer to the monthly demand for electricity, the monthly availability of the municipality's own tur- bo generators and a gas turbine, the monthly capacity of the two power stations and a so-called monthly supply requirement laid down by Escom. The costs to be minimized are the running costs of the turbo generators, the cost of the Escom supply and the running costs of the gas turbine. The cost of the Escom supply consists of an availability charge (Rand/KW) as well as a charge for energy (cent(KWh) used. Escom undertook to supply 56 megawatt each month (except June to August) without levying an availability charge.

With the aid of historical data (1969/70 - 1977/78) a normalized load duration curve was developed for each calender month. This load duration curve was approximated by five linear segments so that it can be amenable for mixed integer programming. The load duration curve was then used to formulate the monthly demand constraints. The peak demand for each of the following 12 months was estimated and then with the aid of the load duration curve the nonpeak demands were calculated.

For each month of the year, for each segment of the load duration curve and for each type of generator there must be an availability constraint (availability of generators). This meant a total of $120(12 \times 5 \times 2)$ availability constraints. The number of availability constraints were reduced to 24 ( 2 per month) by assuming that if a generator supplied power in a given segment of the curve it would also supply power in die segments where increased demands occur. With regard to the electricity supplied by Escom, it was required by Escom that the load sent out during the peak months should not be much higher that the loads sent out during the nonpeak months. It was therefore required to smooth the supply of electricity bought from Escom.

If this was not done the municipality was subject to a severe penalty. Constraints were therefore formulated that smoothed the supply of power bought from Escom.

The following mixed integer programming model was formulated:

(a) Decision variables

$\mathrm{N}(\mathrm{M}, \mathrm{S}, \mathrm{U})$ - The number of generators of type $\mathrm{U}$ running in month $M$ in segment $S$ of the load duration curve.

$\mathbf{M}=1,2, \ldots 12$

$\mathrm{S}=1,2, \ldots \mathrm{S}$

$\mathbf{U}=\mathbf{B}$ (Pretoria West) or $\mathbf{R}$ (Rooiwal)

$\mathrm{X}(\mathrm{M}, \mathrm{S}, \mathrm{U})$ - The running condition of unit $\mathrm{U}$ in segment $\mathrm{S}$ and in month $\mathrm{M}$.

$\mathrm{E}(\mathrm{M}, \mathrm{S}) \quad$ - Power (in $\mathrm{MW}$ ) supplied by Escom in month $\mathrm{M}$ and segment $\mathrm{S}$.

F(M, S) - Free Power supplied by Escom (availability charge excluded) in month $\mathbf{M}$ and segment S.

G(M, S) - Power (MW) supplied by the gas turbine in month $M$ and segment $S$.

(b) Constraints

$\sum_{S} \mathrm{~N}(\mathrm{M}, \mathrm{S}, \mathrm{U}) \leq \mathrm{A}(\mathrm{M}, \mathrm{U})$

$\sum_{U} V(U) \sum_{1}^{S} N(M, I, U)+(W(U)-V(U)) X(M, S, U)$

$+\sum_{1}^{5} \mathrm{E}(\mathrm{M}, \mathrm{I}) \times \sum_{1}^{5} \mathrm{~F}(\mathrm{M}, \mathrm{I})+\sum_{\mathrm{I}-\mathrm{S}}^{5} \mathrm{G}(\mathrm{M}, \mathrm{I}) \geq \mathrm{L}(\mathrm{M}, \mathrm{S})(2)$

$X(M, S, U)-\sum^{\xi} N(M, I, U) \leq 0$ 


$$
\begin{aligned}
& \mathrm{N}(\mathrm{M}, 5, \mathrm{~B}) \geq 1 \\
& \sum_{\mathrm{S}} \mathrm{G}(\mathrm{M}, \mathrm{S}) \leq \mathrm{P}(\mathrm{M}) \\
& 12 \mathrm{~T} \sum_{\mathrm{S}} \mathrm{E}(\mathrm{P}, \mathrm{S})-\sum_{M} \sum_{\mathrm{S}} \mathrm{E}(\mathrm{M}, \mathrm{S}) \leq 0 \\
& \qquad \mathrm{P}=1,2, \ldots,(12)
\end{aligned}
$$

(c) Objective function

Minimize $\sum_{M} \sum_{U} \sum_{S}\left(C_{v}(M, S, U) . N(M, S, U)+C_{w}(M, S, U)\right.$.

$X(M, S, U)+\sum_{M} \sum_{S} C_{E}(M, S,) . E(M, S)+\sum_{M} \sum_{S} C_{F}(M, S)$.

$F(M, S)+\sum_{M} \sum_{S} G_{G}(M, S) G(M, S)$

\section{(d) Parameters}

A(M, U) - The number of type $U$ generators used in month $\mathbf{M}$

V(U) - Minimum capacity (MW) of generator U.

W(U) - Maximum capacity (MW) of generator U.

$\mathbf{L}(\mathbf{M}, \mathbf{S}) \quad$ - Load requirements (MW) in month $\mathbf{M}$ and segment $\mathrm{S}$.

$\mathrm{P}(\mathrm{M})$ - Capacity (MW) of the gas turbine.

$\mathrm{T}$ - Reduction factor $(0,833)$

$\mathrm{C}(\mathrm{M}, \mathrm{S}, \mathrm{U})$ - Running cost of unit $\mathrm{U}$ when producing the minimum amount of power.

$C_{w}(M, S, U)$ - Running cost of unit $U$ (over and above minimum output) when producing the maximum amount of power

$\mathrm{C}_{\mathrm{E}}(\mathrm{M}, \mathrm{S}) \quad-$ Cost of Escom power i.e. availability and energy cost.

$C_{F}(M, S) \quad-$ Cost of Escom power, energy cost only.

$\mathrm{C}_{\mathbf{G}}(\mathrm{M}, \mathrm{S})$ - Running cost of the gas turbine.

The model was run on the Burroughs 7700 computer using the Tempo Programming System. Results obtained thus far from the model indicate that it can provide the Electricity Department with a useful tool in solving a complicated allocation problem.

\section{Verwysings}

1. Day, J.T. Forecasting minimum production costs with linear programming. IEEE Transactions on Power Apparatus and Systems. Vol., Pos-90, No 2, March/April 1971

2. Garver, L.L. Power Generation Scheduling by Integer Programming - Development of Theory. IEEE Trans., Power Apparatus and Systems, 81, 730.
3. Anderson, C.A. Die gebruik van 'n optimiseringsmodel in die implementering van 'n strategiese plan vir die Pretoriase Munisipale Elektrisiteitsafdeling. Ongepubliseerde MBL skripsie, SBL, Universiteit van Suid-Afrika, 1982.

\section{Bylaag 1}

Samevatting van die model

(a) Die veranderlikes

$\mathrm{N}(\mathrm{M}, \mathrm{S}, \mathrm{U})$ - Die aantal tipe $U$ generators wat in maand $\mathrm{M}$ in segment $\mathrm{S}$ van die lasduurkromme loop

$\mathbf{M}=1,2, \ldots, 12$

$S=1,2, \ldots, 5$

$\mathbf{U}=\mathbf{B}$ of $\mathbf{R}$

$\mathrm{X}(\mathrm{M}, \mathrm{S}, \mathrm{U})$ - Omvang van die drywing gelewer deur generator $\mathrm{U}$ bo die minimum in maand $M$ en segment $S$ $0 \leq X(M, S, U) \leq q$ waar $q$ die aantal tipe $U$ generators is.

$\mathrm{E}(\mathrm{M}, \mathrm{S})$ - Drywing (gemeet in $\mathrm{MW}$ ) ingevoer vanaf Evkom in segment $S$ en maand $M$

$\mathbf{F}(\mathrm{M}, \mathrm{S})$ - Gratis drywing (MW) ingevoer vanaf Evkom in segment $S$ en maand $M$.

$G(M, S) \quad-$ Drywing (MW) gelewer deur die gasturbine in maand $M$ en in segment $S$.

(b) Die beperkinge

$\sum_{\mathrm{S}} \mathrm{N}(\mathrm{M}, \mathrm{S}, \mathrm{U}) \leq \mathbf{A}(\mathbf{M}, \mathrm{U})$

$\sum_{U} V(U) \sum_{I=S}^{S} N(M, I, U)+(W(U)-V(U)) \times(M, S, U)+\sum_{I=S}^{S} E(M, I) \times$

$\sum_{I=S}^{5} F(M, l)+\sum_{l=S}^{S} G(M, l) \geq L(M, S)$

$X(M, S, U)+\Sigma_{N}^{S}(M, I, U) \leq 0$

$\mathrm{N}(\mathrm{M}, 5, \mathrm{~B}) \geq \mathrm{I}$

$\sum_{S} G(M, S) \leq P(M)$

$12 T \sum_{S} D(P, S)-\sum_{M} \sum_{S} E(M, S) \leq 0$

$$
P=1,2 \ldots, 12
$$

(c) Die doelfunksie Minimeer $\sum_{M} \sum_{U} \sum_{S}\left(C_{V}(M, S, U) \cdot N(M, S, U)+C_{w}(M, S, U) . X(M, S, U)+\right.$ $\sum_{M} \sum_{S} C_{E}(M, S) \cdot E(M, S)+\sum_{M} \sum_{S} C_{F}(M, S) \cdot F(M, S)+\sum_{M} \sum_{S} C_{G}(M, S) G(M, S)$

(d) Die parameters

$\mathbf{A}(\mathbf{M}, \mathbf{U}) \quad$ - Hoeveetheid $U$ generators beskikbaar in maand $M$

V(U) - Minimum kapasiteit (MW) van generator $U$

W(U) - Maksimum kapasiteit (MW) van generator $U$

Julus $L(M, S)$ - Lasvereistes $(M W)$ in maand $M$ en segment $S$

$\mathbf{P ( M )} \quad-$ Kapasitcit $(\mathrm{MW})$ van die gasturbine

T $\quad-$ Reduksiefaktor $(0,8333)$

Cv(M,S,U) 